\title{
Low-line edge roughness extreme ultraviolet photoresists of organotin carboxylates
}

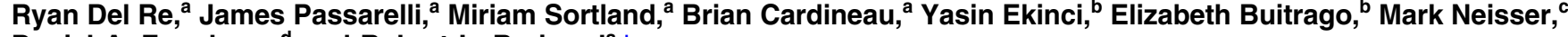 \\ Daniel A. Freedman, ${ }^{\mathrm{d}}$ and Robert L. Brainard ${ }^{\mathrm{a}, *}$ \\ ${ }^{a}$ College of Nanoscale Science and Engineering, 257 Fuller Road, Albany, New York 12203, United States \\ bPaul Scherrer Institut, 5232 Villigen PSI, Switzerland \\ 'Sematech, Albany, New York 12203, United States \\ dState University of New York at New Paltz, 1 Hawk Drive, New Paltz, New York 12561, United States
}

\begin{abstract}
Pure thin films of organotin compounds have been lithographically evaluated using extreme ultraviolet lithography (EUVL, $13.5 \mathrm{~nm}$ ). Twenty compounds of the type $\mathrm{R}_{2} \mathrm{Sn}\left(\mathrm{O}_{2} \mathrm{CR}^{\prime}\right)_{2}$ were spin-coated from solutions in toluene, exposed to EUV light, and developed in organic solvents. Exposures produced negative-tone contrast curves and dense-line patterns using interference lithography. Contrast-curve studies indicated that the photosensitivity is linearly related to the molecular weight of the carboxylate group bound to tin. Additionally, photosensitivity was found to be linearly related to free radical stability of the hydrocarbon group bound directly to tin $(R=$ phenyl, butyl, and benzyl). Dense-line patterning capabilities varied, but two resists in particular show exceptionally good line edge roughness (LER). A resist composed of an amorphous film of $\left(\mathrm{C}_{6} \mathrm{H}_{5} \mathrm{CH}_{2}\right)_{2} \mathrm{Sn}\left(\mathrm{O}_{2} \mathrm{CC}\left(\mathrm{CH}_{3}\right)_{3}\right)_{2}$ (1) achieved $1.4 \mathrm{~nm}$ LER at 22-nm half-pitch patterning and a resist composed of $\left(\mathrm{C}_{6} \mathrm{H}_{5} \mathrm{CH}_{2}\right)_{2} \mathrm{Sn}\left(\mathrm{O}_{2} \mathrm{CC}_{6} \mathrm{H}_{5}\right)_{2}$ (2) achieved $1.1 \mathrm{~nm} \mathrm{LER}$ at 35-nm half-pitch at high exposure doses $\left(600 \mathrm{~mJ} / \mathrm{cm}^{2}\right)$. Two photoresists that use olefin-based carboxylates, $\left(\mathrm{C}_{6} \mathrm{H}_{5} \mathrm{CH}_{2}\right)_{2} \mathrm{Sn}\left(\mathrm{O}_{2} \mathrm{CCH}=\mathrm{CH}_{2}\right)_{2}(3)$ and $\left(\mathrm{C}_{6} \mathrm{H}_{5} \mathrm{CH}_{2}\right)_{2} \mathrm{Sn}\left(\mathrm{O}_{2} \mathrm{CC}\left(\mathrm{CH}_{3}\right)=\mathrm{CH}_{2}\right)_{2}(4)$, demonstrated better photospeeds $\left(5 \mathrm{~mJ} / \mathrm{cm}^{2}\right.$ and $\left.27 \mathrm{~mJ} / \mathrm{cm}^{2}\right) \mathrm{but}$ worse LER. $\odot 2015$ Society of Photo-Optical Instrumentation Engineers (SPIE) [DOI: 10.1117/1.JMM.14.4.043506]
\end{abstract}

Keywords: extreme ultraviolet; organometallic; resist; photoresist; tin; line edge roughness; line width roughness.

Paper 15064P received Apr. 22, 2015; accepted for publication Sep. 4, 2015; published online Nov. 9, 2015.

\section{Introduction}

Traditional chemically amplified photoresists have been used in the microelectronics industry for over 20 years. ${ }^{1,2}$ These lithographic systems have enormous capability and have achieved the photolithographic performance that allowed the industry to follow Moore's law. ${ }^{3}$ However, the cost and complexity of achieving smaller feature sizes are increasing with each new technology node. Extreme ultraviolet lithography (EUVL, $13.5 \mathrm{~nm}$ ) continues to rely on conventional chemically amplified photoresists, but these resists may be unable to meet the needs of future technology nodes. ${ }^{4,5}$ EUV photons $(92 \mathrm{eV})$ interact with matter differently than do $193-\mathrm{nm}$ photons $(6.4 \mathrm{eV})$, therefore, the fundamental design of photoresists may need to change to obtain the best lithographic performance for EUVL. As film thickness decreases to compensate for smaller patterning without line collapse, ${ }^{6}$ organic films may be unable to absorb the photons efficiently ${ }^{7}$ which may lead to poorer sensitivity and poorer line edge roughness (LER). ${ }^{8}$ Etch resistance may also be inadequate in these thinner, organic films. ${ }^{9,10}$ We have previously reported on a new resist system, molecular organometallic resists (MORE for EUV), that seeks to overcome these potential obstacles. By using elements that have high-EUV optical density, we intend to create molecular films that absorb greater numbers of EUV photons than do purely organic resists and to create resists with better resolution, sensitivity, and LER.

\footnotetext{
*Address all correspondence to: Robert L. Brainard, E-mail: rbrainard@
} sunycnse.com
Here, we present recent lithographic results of several MORE mononuclear tin compounds that have been spin coated as thin films on wafers and exposed to EUV light. We have synthesized a series of tin compounds of the general type $\mathrm{R}_{2} \mathrm{Sn}\left(\mathrm{O}_{2} \mathrm{CR}^{\prime}\right)_{2}$, to study the effects of increasing ligand bulk and increasing $\mathrm{Sn}-\mathrm{R}$ bond energy on photosensitivity and lithographic performance. Photosensitivity was quantified by finding the $E_{\max }$ (energy needed to achieve maximum thickness after development) from the contrast curves and patterning was evaluated using $E_{\text {size }}\left(\mathrm{mJ} / \mathrm{cm}^{2}\right)$, LER $(\mathrm{nm})$, and resolution $(\mathrm{nm})$. Although the sensitivity of many of these compounds is poor $\left(E_{\text {size }}=50\right.$ to $\left.600 \mathrm{~mJ} / \mathrm{cm}^{2}\right)$, they are capable of good resolution and excellent LER. In particular, dibenzyltin dipivalate [1, Fig. 1(a)] resolves 16-nm half-pitch dense lines with 2.1-nm LER and resolves 22$\mathrm{nm}$ half-pitch dense lines with 1.4-nm LER [Fig. 1(b)]. We also see a linear trend when we compare molecular weights with $E_{\max }$ within a particular compound family [Fig. 2(b)].

\section{Results and Discussion}

A series of compounds of the type $\mathrm{R}_{2} \mathrm{Sn}\left(\mathrm{O}_{2} \mathrm{CR}^{\prime}\right)_{2}$ have been prepared using procedures modified from experimental methods found in literature. ${ }^{11,12}$ Toluene solutions of these compounds were spin-coated onto silicon wafers as thin films. The resists were then exposed to EUV light at the Paul Scherrer Institut (PSI) for evaluation of both contrast curves and dense line and space patterning. The exposed wafers were developed in hexanes for 5 to $25 \mathrm{~s}$ revealing negative-tone imaging. Although toluene and hexanes are

\footnotetext{
$1932-5150 / 2015 / \$ 25.00$ @ 2015 SPIE
} 
(a)

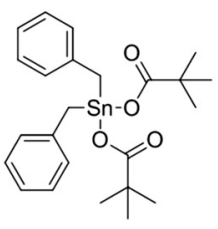

$\underline{(1)}$ (b)

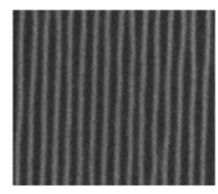

Resolution: $16 \mathrm{~nm}$

LER: $\quad 2.1 \mathrm{~nm}$

Dose: $\quad 600 \mathrm{~mJ} / \mathrm{cm}^{2}$

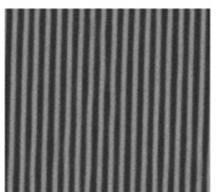

Resolution: $22 \mathrm{~nm}$ LER: $\quad 1.4 \mathrm{~nm}$ Dose: $\quad 600 \mathrm{~mJ} / \mathrm{cm}^{2}$

Fig. 1 (a) Structure of compound $1,\left(\mathrm{C}_{6} \mathrm{H}_{5} \mathrm{CH}_{2}\right)_{2} \mathrm{Sn}\left(\mathrm{O}_{2} \mathrm{C}\left(\mathrm{C}\left(\mathrm{CH}_{3}\right)_{3}\right)\right)_{2}$ and (b) dense-line patterning capabilities of compound 1 exhibiting low line edge roughness (LER).

not traditional solvents used by the microelectronics industry, spin-coating from toluene created the highest quality films and developing with hexanes led to the best dissolution contrast when compared to traditional industrial solvents.

\subsection{Dependence of Molecular Weight on Photosensitivity $\left(E_{\max }\right)$}

Contrast curve exposures of resists at PSI give a good measure of their relative photosensitivities. Previously, Cardineau et al., ${ }^{13}$ reported that the sensitivities of tin-oxo clusters improve as the molecular weight of the counter ions decreases. We have lithographically evaluated a series of mononuclear $\mathrm{R}_{2} \mathrm{Sn}$ (carboxylate) $)_{2}$ compounds and found little correlation when plotting $E_{\max }$ versus molecular weight of the compounds [Fig. 2(a)]. However, when plotting $E_{\max }$ versus carboxylate variations with $\mathrm{R}$ held constant [Fig. 2(b)], we observe a molecular weight dependence with good correlation. This relationship between $E_{\max }$ and MW may indicate that the efficiency of the negative-tone behavior (e.g., cross-linking) increases with decreasing distance between tin atoms.

\section{2 $E_{\text {size }}$ Dependence on Molecular Weight}

We patterned dense lines with interference lithography at PSI and found that the same linear dependence held between molecular weight and $E_{\text {size }}$ with dibenzyltin dicarboxylates that are nonacrylate based (Fig. 3). Interestingly, dibenzyltin diacrylate (3) and dibenzyltin dimethacrylate (4) deviated from this linear trend and are much more sensitive than would be predicted based on molecular weight arguments

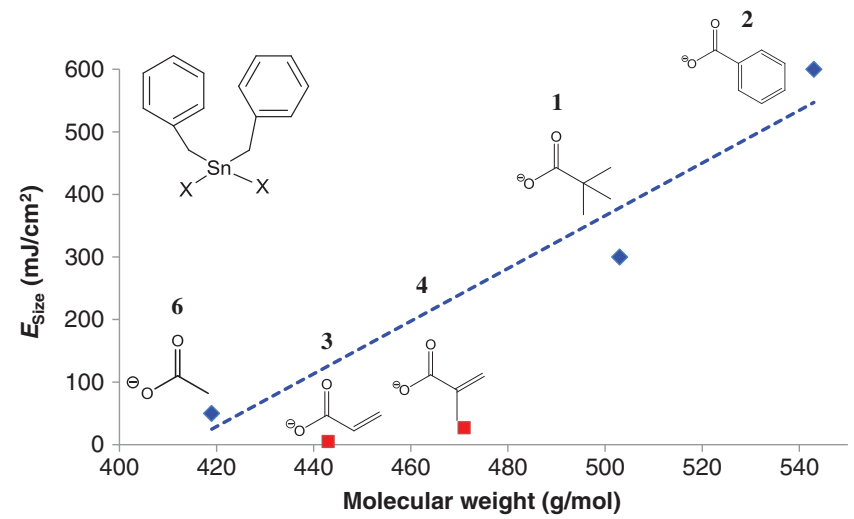

Fig. 3 50-nm dense-line patterning shows the same linear dependence with a significant deviation when analyzing acrylate-based resists.

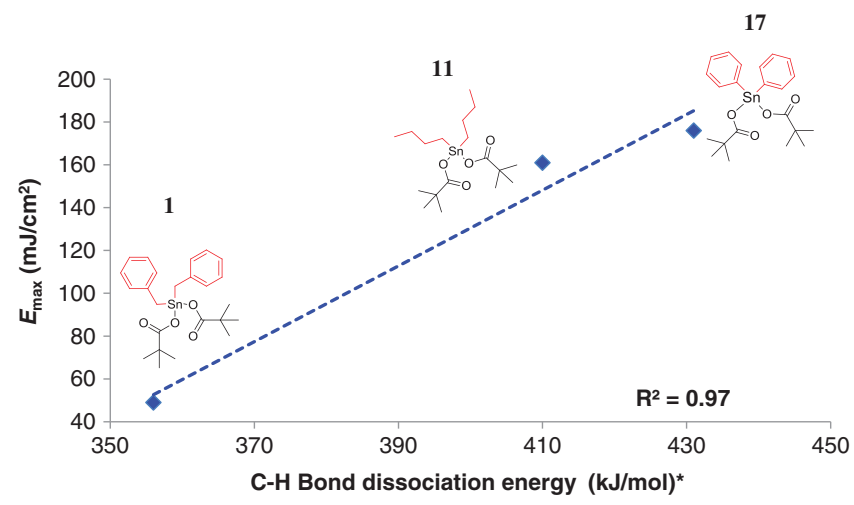

Fig. 4 Variation of $\mathrm{C}-\mathrm{H}$ bond strength shows an inverse relationship with sensitivity. This may indicate that this bond strength plays an important role during photoexposure.

alone. In this case, the deviation may be attributed to a different and more efficient mechanism of exposure, similar to olefin containing resists reported by Passarelli et al., ${ }^{14}$ in which crosslinking occurs through free-radical polymerization.

\subsection{Tin-Carbon Bond Strength and $E_{\max }$ Dependence}

We wanted to explore the effect of the tin-carbon bond strength on the sensitivity of three resists. However, there are no experimental measurements available of direct
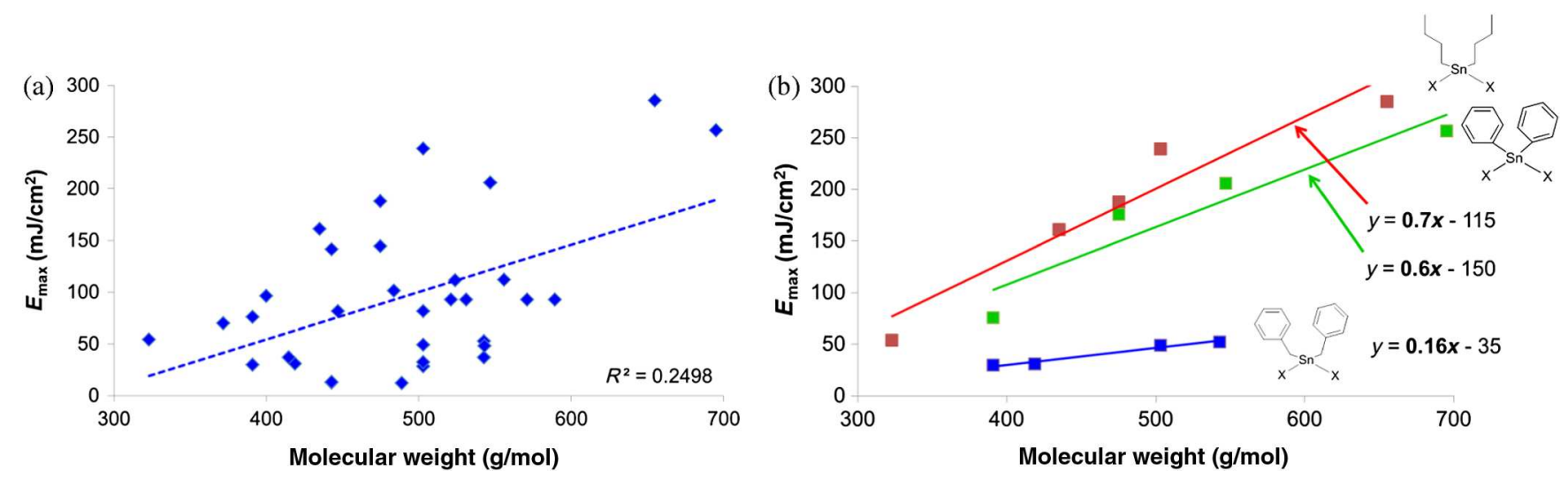

Fig. 2 (a) Comparing a wide variety of organotin carboxylates shows little correlation of data. However (b) strong correlations exist when comparing a particular family of compounds. 


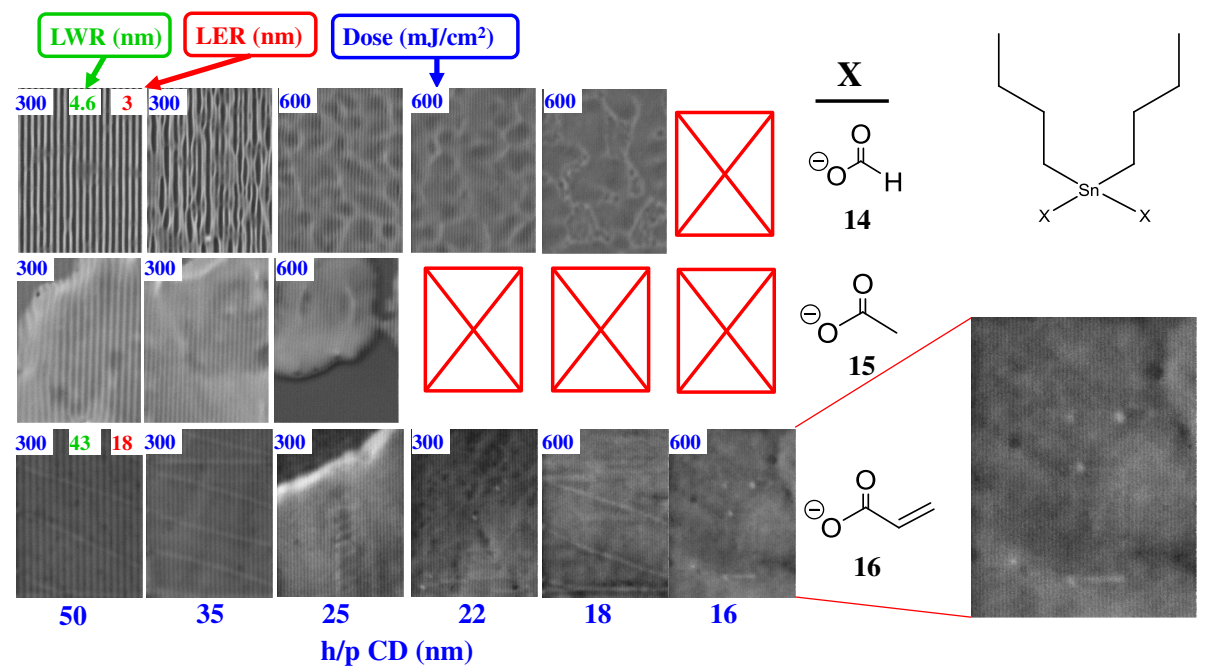

Fig. 5 Dense-line patterning capabilities of dibutyltin dicarboxylates. All of the films exhibited poor film quality after development.

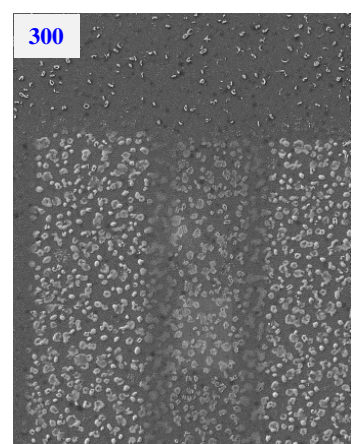

$3 \mathrm{kx}$

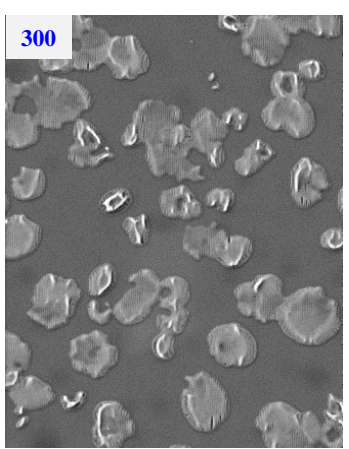

$20 \mathrm{kx}$

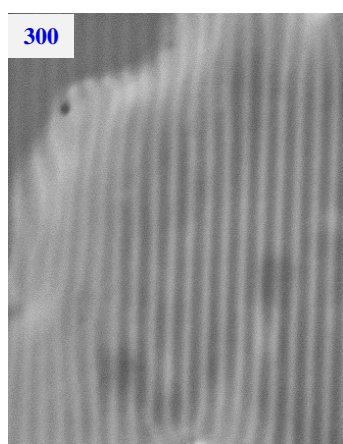

$150 \mathrm{kx}$

Fig. 6 Strange patterning phenomenon of dibutyltin diacetate (15). Each island shows patterning with no patterning in the spaces.

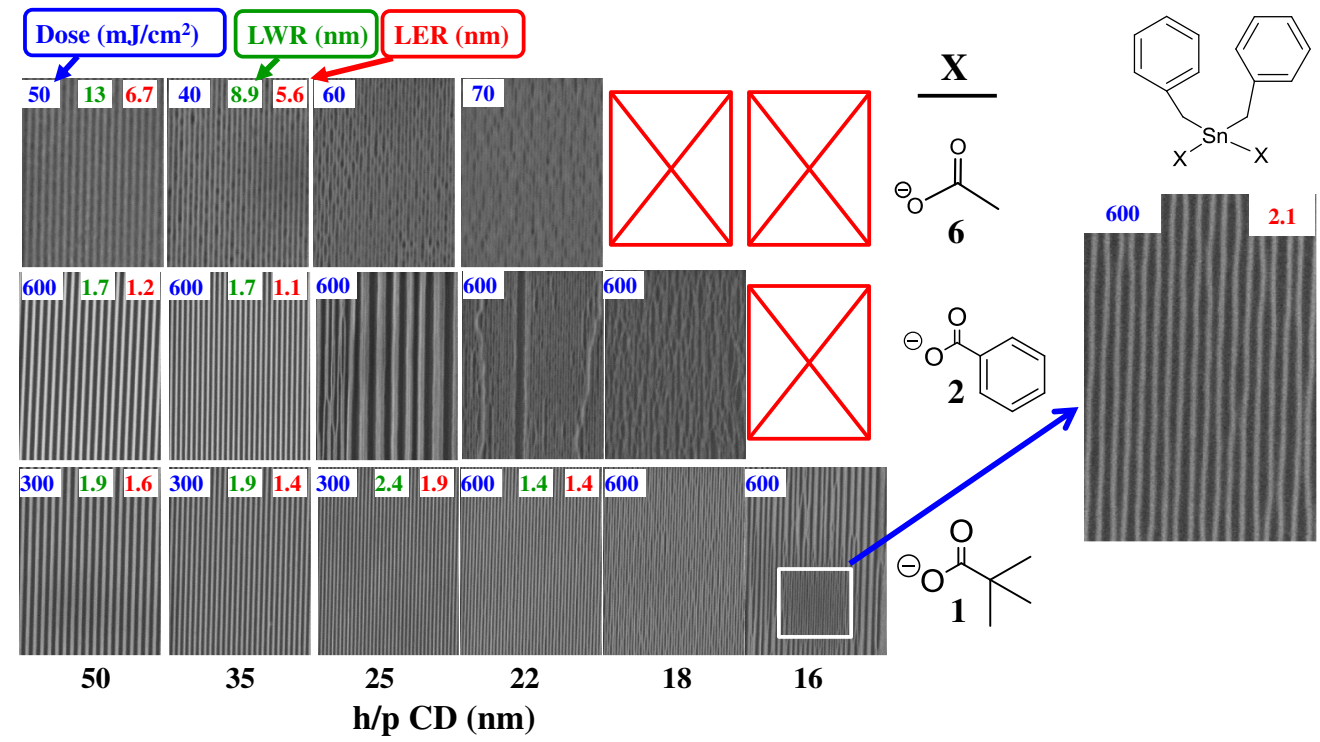

Fig. 7 Dense-line patterning capabilities of dibenzyltin dicarboxylates. These resists achieved the highest resolution and lowest LER of any metal based resist evaluated by our group. 


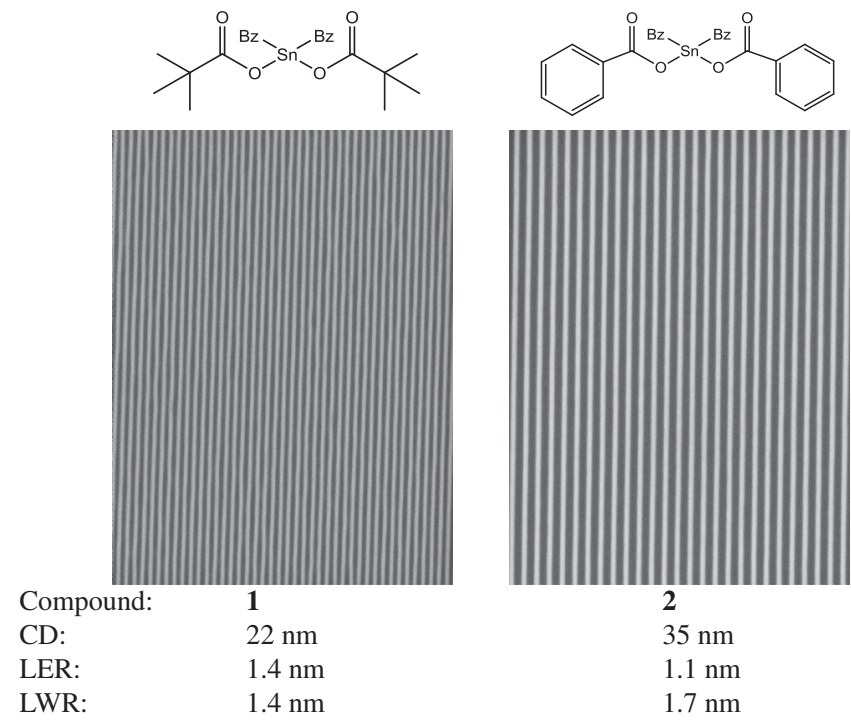

Fig. 8 Compounds 1 and 2 display high resolution patterning with extremely low LER.

bond dissociation energies between $\mathrm{Sn}-\mathrm{R}$ in these cases, but the $\mathrm{C}-\mathrm{H}$ bond dissociation energies have been measured ${ }^{15-17}$ and we used these values as a measure of relative bond strength between $\mathrm{Sn}-\mathrm{R}$. Figure 4 shows the $E_{\max }$ of compounds 1, 11, and 17: $\mathrm{R}_{2} \mathrm{Sn}\left(\mathrm{O}_{2} \mathrm{C}\left(\mathrm{C}\left(\mathrm{CH}_{3}\right)_{3}\right)_{2}\right.$ where $\mathrm{R}=$ phenyl, butyl, benzyl plotted as a function of $\mathrm{C}-\mathrm{H}$ bond-strength. The inverse relation suggests that photolytic cleavage occurs at the $\mathrm{Sn}-\mathrm{C}$ bond during exposure.
Decreasing the $\mathrm{Sn}-\mathrm{C}$ bond strength further may help improve photospeeds.

\subsection{Imaging of Tin Dicarboxylates}

Imaging was performed at the Swiss Light Source (SLS) at PSI using interference lithography. ${ }^{18}$ Figure 5 shows dense line/space patterns of three dibutyltin compounds. Although these resists exhibit pattern modulation to $16 \mathrm{~nm}$, the film quality is poor. Figure 6 shows $(\mathrm{Bu})_{2} \mathrm{Sn}\left(\mathrm{O}_{2} \mathrm{CCH}_{3}\right)_{2}$ (15) at increasing levels of magnification. At low magnification, many light-colored spots are present in the exposed areas. At higher magnification, dense-line patterns are visible. All of the dibutyltin complexes required high exposures and had poor LER.

Figure 7 shows dense line/space patterning capabilities of various dibenzyl tin compounds. The sensitivities show a large range of values ( 50 to $600 \mathrm{~mJ} / \mathrm{cm}^{2}$ ) corresponding to a wide range of resolution capabilities. Dibenzyltin dipivalate (1) has achieved 16-nm dense patterning at a high-exposure dose of $600 \mathrm{~mJ} / \mathrm{cm}^{2}$. The most remarkable quality of two of these dibenzyl tin resists is the extremely low LER, $1.4 \mathrm{~nm}$ (dibenzyltin dipivalate, 1) and $1.1 \mathrm{~nm}$ (dibenzyltin dibenzoate, 2) (Fig. 8).

\subsection{Fast Resists with Ligands Containing Olefins}

Although the exposure doses of most tin carboxylate photoresists were very high, we discovered two molecules (dibenzyltin diacrylate, $\mathbf{3}$ and dibenzyltin dimethacrylate, 4) that required much lower exposure doses $\left(5,27 \mathrm{~mJ} / \mathrm{cm}^{2}\right)$ to

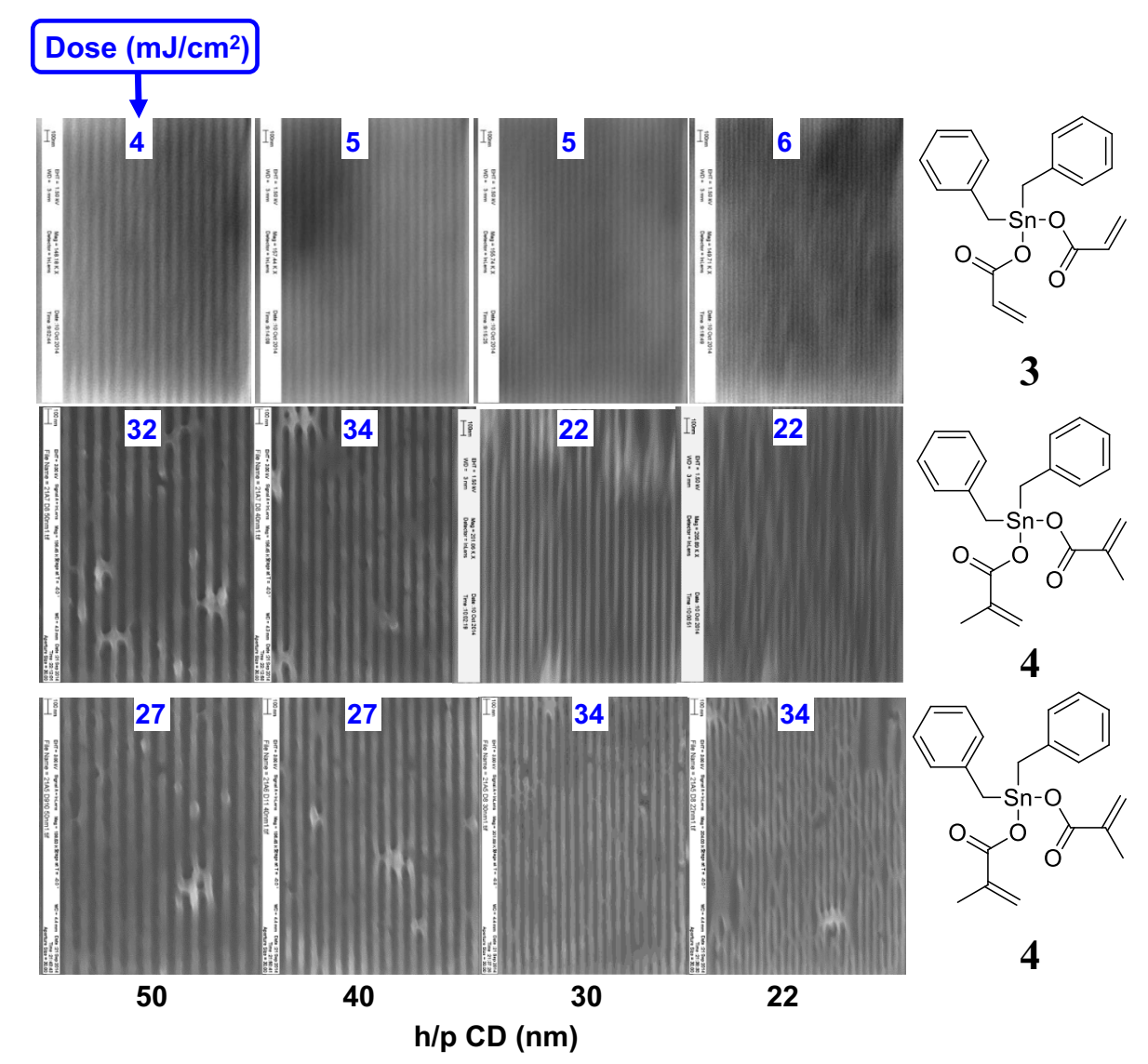

Fig. 9 Dibenzyltin acrylates displayed much better photospeeds at a cost of resolution and LER. 
print dense lines (Fig. 9). We propose that these molecules undergo a more efficient exposure mechanism, possibly utilizing a free radical polymerization after an initiation event. These free-radical polymerization reactions should crosslink the film, thereby decreasing the dissolution rate in the exposed areas.

\section{Conclusions}

We have evaluated the EUV lithographic capabilities of 20 organotin dicarboxylates. We systematically evaluated the imaging capabilities of these compounds as a function of the identity of the alkyl and carboxylic acid groups. We discovered a general trend within three classes of compounds ( $\mathrm{R}=$ phenyl, butyl, benzyl) that showed improving sensitivities with decreasing molecular weight. Variations of the organic substituent bound directly to tin (phenyl, butyl, benzyl) showed a correlation between resist sensitivity and the stability of the corresponding organic free radical. We concluded that the alkyl-tin bond strength is very important in determining the ultimate sensitivity and is the most likely bond cleaved during exposure. Increased molecular weight due to carboxylate variations may affect the resist sensitivity by either reducing the film's mass density and EUV optical density or by acting as physical spacers that reduce intermolecular interactions after exposure.

We have printed dense lines of some of these compounds and have resolved features to $16 \mathrm{~nm}$ with significant pattern collapse at high-exposure doses $\left(600 \mathrm{~mJ} / \mathrm{cm}^{2}\right)$. Perhaps the most remarkable quality observed is the extremely low LER of two resists (1.4 and $1.1 \mathrm{~nm}$, Fig. 8). When we introduced ligands that contained olefins to dibenzyl tin systems $(\mathbf{3}, \mathbf{4})$, we found that a much lower exposure dose $\left(5,27 \mathrm{~mJ} / \mathrm{cm}^{2}\right.$, respectively) was needed to print dense lines (Fig. 9). These molecules may be capable of polymerizing through a free radical mechanism, leading to more efficient crosslinking in the film.

\section{Experimental Methods}

\subsection{Instruments}

${ }^{1} \mathrm{H}$ nuclear magnetic resonance (NMR) spectra were measured with a Bruker $400 \mathrm{MHz}$ spectrometer using tetramethyl silane as an internal reference. All chemical shifts are reported as parts per million. Tin-H coupling constants are written in the as $\mathrm{J}_{\mathrm{H}-\mathrm{Sn}}$. All other reported coupling constants are $\mathrm{H}-\mathrm{H}$.

\subsection{Resist Formulation and Imaging}

Resist formulations were made by dissolving solids in toluene and filtering through a $0.2-\mu \mathrm{m}$ PTFE filter. Formulations were spin-coated onto a custom underlayer (crosslinked hydroxyethyl methacrylate/methyl methacrylate copolymers) on 4-inch silicon wafers. 40 to 60 -nm thick resist films were made by adjusting spin-speed and formulation concentration. Resist films were then exposed with 13.5-nm radiation and developed with a hexanes solvent. Exposures were performed at PSI on the XIL-II beamline using open-frame exposures to prepare contrast curves or using interference lithography for dense-line patterning.

\subsection{Scanning Electron Microscope Metrology}

Scanning electron microscope micrographs were collected at PSI on a Zeiss Supra VP55. Accelerating voltage was set between 1 and $2 \mathrm{KeV}$ and the working distance was $4 \mathrm{~mm}$. All images were at either $150 \mathrm{kX}$ or $200 \mathrm{kX}$ magnification.

\subsection{Line Edge Roughness Analysis}

All LER values were obtained from the analysis of the SEM micrographs in SuMMIT Lithography Image Analysis software.

\subsection{General Synthetic Procedure}

All reactions were carried out under a nitrogen environment. The reagents n-dibutyltin dichloride, n-dibutyltin hydroxide oxide, and diphenyltin dichloride were purchased from Alfa Aesar. All other reagents were purchased from SigmaAldrich. All reagents were used as received unless specified. Dibenzyltin dibromide (21) was prepared by a procedure found in the literature. ${ }^{19}$

\subsubsection{Synthetic procedure for compounds 1 through 13}

The general procedure was adapted from procedures found in the chemistry literature. ${ }^{11,12,19}$

Method A. $\mathrm{R}_{2} \mathrm{SnX}_{2}(\mathrm{R}=$ Phenyl, Benzyl; $\mathrm{X}=\mathrm{Cl}, \mathrm{Br})$ (2 mmol) was combined with the sodium salt of the acid (4 mmol) in dichloromethane or hexanes $(20 \mathrm{~mL})$ in a 50 $\mathrm{mL}$ round-bottom flask, equipped with a stir bar and reflux condenser. The mixture was refluxed for $3 \mathrm{~h}$, cooled, and filtered through a small pore glass frit. The filtrate was evaporated to dryness at reduced pressure to a white powder and was used as is.

Method B. The acid (4 mmol) was combined with dichloromethane $(10 \mathrm{~mL})$ in a $50-\mathrm{mL}$ round-bottom flask equipped with a stir bar. Triethylamine $(0.56 \mathrm{~mL}$, $4 \mathrm{mmol}$ ) was added slowly to the stirring solution. After 5 min of mixing, $\mathrm{R}_{2} \mathrm{MX}_{2}(0.744 \mathrm{~g}, 2 \mathrm{mmol})$ in dichloromethane $(10 \mathrm{~mL})$ was added to the reaction mixture. The solution was mixed until the reaction was completed, generally 0.5 to $3 \mathrm{~h}$. The reaction mixture was filtered through a small pore glass frit and the filtrate was evaporated under reduced pressure to approximately $5 \mathrm{~mL}$. The mixture was extracted with benzene and any impurities were filtered off. The filtrate was evaporated under reduced pressure to a powder which was used as is.

Dibenzylstannanediyl bis(2,2-dimethylpropanoate) (1). Trimethylacetic acid $(0.409 \mathrm{~g}, 4 \mathrm{mmol})$ was used as the acid. $0.32 \mathrm{~g}$ were obtained ( $32 \%$ yield). ${ }^{1} \mathrm{H}$ NMR $($ Chloroform- $d) \quad \delta$ 7.28-6.92 (m, 10H), $2.95 \quad(\mathrm{~s}$, $\left.J_{\mathrm{H}-\mathrm{Sn}}=84.8,88.9,136.6 \mathrm{~Hz}, 4 \mathrm{H}\right), 1.02(\mathrm{~s}, 18 \mathrm{H})$.

Dibenzylstannanediyl dibenzoate (2). benzoic acid $(0.488 \mathrm{~g}, 4 \mathrm{mmol})$ was used as the acid. $0.83 \mathrm{~g}$ were obtained (76\% yield). ${ }^{1} \mathrm{H}$ NMR (Chloroform- $d$ ) $\delta$ $7.98(\mathrm{~d}, J=7.7 \mathrm{~Hz}, 4 \mathrm{H}), 7.55(\mathrm{t}, J=7.5 \mathrm{~Hz}, 2 \mathrm{H})$, $7.40(\mathrm{t}, J=7.7 \mathrm{~Hz}, 4 \mathrm{H}), 7.29-6.66(\mathrm{~m}, 10 \mathrm{H}), 3.14$ $\left(\mathrm{s}, J_{\mathrm{H}-\mathrm{Sn}}=89.5,93.6,137.3 \mathrm{~Hz}, 4 \mathrm{H}\right)$.

Dibenzylstannanediyl diacrylate (3). acrylic acid $(0.288 \mathrm{~g}$, $4 \mathrm{mmol}$ ) was used as the acid. $0.52 \mathrm{~g}$ were obtained 
(59\% yield). ${ }^{1} \mathrm{H}$ NMR (Chloroform- $d$ ) $\delta$ 7.30-6.90 (m, $10 \mathrm{H}), 6.33$ (d, $J=17.3 \mathrm{~Hz}, 2 \mathrm{H}), 6.02$ (dd, $J=17.2$, $10.3 \mathrm{~Hz}, 2 \mathrm{H}), 5.81(\mathrm{~d}, J=10.3 \mathrm{~Hz}, 2 \mathrm{H}), 3.02(\mathrm{~s}$, $\left.J_{\mathrm{H}-\mathrm{Sn}}=88.9,92.9,139.1 \mathrm{~Hz}, 4 \mathrm{H}\right)$.

Dibenzylstannanediyl bis(2-methylacrylate) (4). methacrylic acid $(0.344 \mathrm{~g}, 4 \mathrm{mmol})$ was used as the acid. $0.51 \mathrm{~g}$ were obtained $(54 \%$ yield $) .{ }^{1} \mathrm{H} \quad \mathrm{NMR}$ (Chloroform- $d$ ) $\delta$ 7.37-6.93 (m, 10H), $6.03(\mathrm{~s}, 2 \mathrm{H})$, $5.48(\mathrm{~d}, J=2.1 \mathrm{~Hz}, 2 \mathrm{H}), 3.02 \quad\left(\mathrm{~s}, \quad J_{\mathrm{H}-\mathrm{Sn}}=89.1\right.$, 93.4, $137 \mathrm{~Hz}, 4 \mathrm{H}), 1.80$ (s, 6H).

Dibenzylstannanediyl diformate (5). formic acid $(0.184 \mathrm{~g}$, $4 \mathrm{mmol}$ ) was used as the acid. $0.32 \mathrm{~g}$ were obtained (41\% yield). ${ }^{1} \mathrm{H}$ NMR (Chloroform- $d$ ) $\delta 8.2$ (s, 2H), $7.61-6.48 \quad(\mathrm{~m}, \quad 11 \mathrm{H}), \quad 3.21 \quad\left(\mathrm{~s}, \quad J_{\mathrm{H}-\mathrm{Sn}}=73.9\right.$, $154.8 \mathrm{~Hz}, 4 \mathrm{H})$.

Dibenzylstannanediyl diacetate (6). acetic acid $(0.24 \mathrm{~g}$, $4 \mathrm{mmol}$ ) was used as the acid. $0.5 \mathrm{~g}$ were obtained (60\% yield). ${ }^{1} \mathrm{H}$ NMR (Chloroform- $d$ ) $\delta$ 7.51-6.64 $(\mathrm{m}, 10 \mathrm{H}), 2.98\left(\mathrm{~s}, J_{\mathrm{H}-\mathrm{Sn}}=89.2,137.2 \mathrm{~Hz}, 4 \mathrm{H}\right), 1.87$ $(\mathrm{s}, 6 \mathrm{H})$.

Dibenzylstannanediyl bis(2-phenylacetate) (7). phenylacetic acid $(0.545 \mathrm{~g}, 4 \mathrm{mmol})$ was used as the acid. $0.68 \mathrm{~g}$ were obtained (59\% yield). ${ }^{1} \mathrm{H}$ NMR (Chloroform- $d$ ) $\delta$ 7.39-7.20 (m, 6H), 7.20-6.99 (m, 10H), 6.99-6.83 (m, $4 \mathrm{H}), 3.40(\mathrm{~s}, 4 \mathrm{H}), 2.95\left(\mathrm{~s}, J_{\mathrm{H}-\mathrm{Sn}}=86.8,137.5 \mathrm{~Hz}, 4 \mathrm{H}\right)$.

Dibenzylstannanediyl bis(2,2-diphenylacetate) (8). diphenylacetic acid $(0.849 \mathrm{~g}, 4 \mathrm{mmol})$ was used as the acid. The compound was crystallized in hexanes. $0.96 \mathrm{~g}$ were obtained (66\% yield). ${ }^{1} \mathrm{H}$ NMR (Chloroform- $\left.d\right) \delta 7.31-$ $7.13(\mathrm{~m}, 20 \mathrm{H}), 7.07-6.94(\mathrm{~m}, 6 \mathrm{H}), 6.85-6.73(\mathrm{~m}, 4 \mathrm{H})$, $4.86(\mathrm{~s}, 2 \mathrm{H}), 2.94\left(\mathrm{~s}, J_{\mathrm{H}-\mathrm{Sn}}=84.4,137.6 \mathrm{~Hz}, 4 \mathrm{H}\right)$.

Diphenylstannanediyl diacetate (9). acetic acid $(0.24 \mathrm{~g}$, $4 \mathrm{mmol}$ ) was used as the acid. $0.26 \mathrm{~g}$ were obtained (33\% yield). ${ }^{1} \mathrm{H}$ NMR (Chloroform- $d$ ) $\delta$ 8.12-6.55 $(\mathrm{m}, 11 \mathrm{H}), 2.62-0.53(\mathrm{~m}, 6 \mathrm{H})$.

Diphenylstannanediyl diacrylate (10). acrylic acid $(0.288 \mathrm{~g}$, $4 \mathrm{mmol}$ ) was used as the acid. $0.45 \mathrm{~g}$ were obtained (54\% yield). ${ }^{1} \mathrm{H}$ NMR (Chloroform- $d$ ) $\delta$ 7.96-7.31 $(\mathrm{m}, 10 \mathrm{H}), 6.44(\mathrm{~d}, J=17.3 \mathrm{~Hz}, 2 \mathrm{H}), 6.22$ (dd, $J=17.3,10.2 \mathrm{~Hz}, 2 \mathrm{H}), 5.83$ (d, $J=10.3 \mathrm{~Hz}, 2 \mathrm{H})$.

Diphenylstannanediyl bis(2,2-dimethylpropanoate) (11). trimethylacetic acid $(0.409 \mathrm{~g}, 4 \mathrm{mmol})$ was used as the acid. $0.2 \mathrm{~g}$ were obtained $\left(21 \%\right.$ yield). ${ }^{1} \mathrm{H}$ NMR (Chloroform- $d$ ) $\delta$ 7.88-6.70 (m, 10H), $1.17(\mathrm{~s}, 18 \mathrm{H})$.

Diphenylstannanediyl bis(2-phenylacetate) (12). phenylacetic acid $(0.545 \mathrm{~g}, 4 \mathrm{mmol})$ was used as the acid. $0.31 \mathrm{~g}$ were obtained $\left(28 \%\right.$ yield). ${ }^{1} \mathrm{H} \quad \mathrm{NMR}$ (Chloroform-d) $\delta$ 7.77-6.86 (m, 20H), 3.59 (s, 4H).

Diphenylstannanediyl bis(2,2-diphenylacetate) (13). diphenylacetic acid $(0.849 \mathrm{~g}, 4 \mathrm{mmol})$ was used as the acid. $0.63 \mathrm{~g}$ were obtained (45\% yield). ${ }^{1} \mathrm{H}$ NMR (Chloroform- $d$ ) $\delta$ 7.66-7.06 (m, 33H), $5.15(\mathrm{~s}, 2 \mathrm{H})$.

\subsubsection{Synthetic procedure for compounds 14 through 20}

Method A. Dibutyltin dichloride (0.5 g, 2 mmol) was combined with the acid $(4 \mathrm{mmol})$ and toluene $(20 \mathrm{~mL})$ in a 50 $\mathrm{mL}$ round-bottom flask equipped with a stir bar, dean stark water trap, and reflux condenser. The solution was heated and allowed to reflux for $1 \mathrm{~h}$ and then filtered through a fine pore glass frit. The filtrate was evaporated under reduced pressure to form a white powder. The final product was obtained through crystallization using hexanes, if possible.

Method B. The acid (4 mmol) and dichloromethane $(10 \mathrm{~mL})$ was added to a $50-\mathrm{mL}$ round-bottom flask equipped with a stir bar. Triethylamine $(0.56 \mathrm{~g}, 4 \mathrm{mmol})$ was added slowly to the stirring solution. After 5 min of mixing, $n$-dibutyltin dichloride $(0.5 \mathrm{~g}, 2 \mathrm{mmol})$ in dichloromethane $(10 \mathrm{~mL})$ was added to the reaction mixture. The solution was mixed until the reaction was completed, generally 1 to $3 \mathrm{~h}$. The reaction mixture was then filtered through a small pore glass frit and the filtrate was evaporated under reduced pressure to approximately $5 \mathrm{~mL}$. The mixture was extracted with a saturated sodium bicarbonate solution three times. The organic layer was dried on sodium sulfate and the final product was crystallized from hexanes or dichloromethane/ hexanes.

Dibutylstannanediyl diformate (14). formic acid $(0.184 \mathrm{~g}$, $4 \mathrm{mmol}$ ) was used as the acid. The final product was an oil and crystallization was not possible. $0.15 \mathrm{~g}$ were obtained $\left(23 \%\right.$ yield). ${ }^{1} \mathrm{H}$ NMR (Chloroform- $d$ ) $\delta \quad 8.44(\mathrm{~s}, 2 \mathrm{H}), 1.70-1.56(\mathrm{~m}, 4 \mathrm{H}), 1.30 \quad(\mathrm{dt}$, $J=30.1,7.2 \mathrm{~Hz}, 8 \mathrm{H}), 0.87(\mathrm{t}, J=7.2 \mathrm{~Hz}, 6 \mathrm{H})$.

Dibutylstannanediyl diacetate (15). acetic acid (0.24 g, $4 \mathrm{mmol}$ ) was used as the acid. The final product was an oil and crystallization was not possible. $0.32 \mathrm{~g}$ were obtained (45\% yield). ${ }^{1} \mathrm{H}$ NMR (Chloroform- $d$ ) $\delta 2.06$ (s, 6H), 1.81-1.44 (m, 8H), 1.35 (hd, $J=7.9$, $7.3,4.5 \mathrm{~Hz}, 4 \mathrm{H}), 0.88(\mathrm{t}, J=7.3 \mathrm{~Hz}, 6 \mathrm{H})$.

Dibutylstannanediyl diacrylate (16). acrylic acid (0.288 g, $4 \mathrm{mmol}$ ) was used as the acid. The compound was crystallized in hexanes. $0.25 \mathrm{~g}$ were obtained (33\% yield). ${ }^{1} \mathrm{H}$ NMR (Chloroform-d) $\delta$ 6.55-5.66 (m, 6H), 1.87$1.45(\mathrm{~m}, 8 \mathrm{H}), 1.43-1.14(\mathrm{~m}, 4 \mathrm{H}), 0.86(\mathrm{t}, \quad J=$ $7.4 \mathrm{~Hz}, 6 \mathrm{H})$.

Dibutylstannanediyl bis(2,2-dimethylpropanoate) (17). trimethylacetic acid $(0.409 \mathrm{~g}, 4 \mathrm{mmol})$ was used as the acid. The compound was crystallized in hexanes. $0.64 \mathrm{~g}$ were obtained $\left(74 \%\right.$ yield). ${ }^{1} \mathrm{H} \quad \mathrm{NMR}$ (Chloroform- $d) \delta 1.75-1.41(\mathrm{~m}, 8 \mathrm{H}), 1.39-1.26(\mathrm{~m}$, $4 \mathrm{H}), 1.19(\mathrm{~s}, 18 \mathrm{H}), 0.85(\mathrm{t}, J=7.4 \mathrm{~Hz}, 6 \mathrm{H})$.

Dibutylstannanediyl dibenzoate (18). benzoic acid $(0.488 \mathrm{~g}$, $4 \mathrm{mmol}$ ) was used as the acid. The compound was crystallized in 1:9 dichloromethane: hexanes. $0.12 \mathrm{~g}$ were obtained (13\% yield). ${ }^{1} \mathrm{H}$ NMR (Chloroform- $d$ ) $\delta$ 8.45-6.73 (m, 10H), 1.95-0.77 (m, 18H).

Dibutylstannanediyl bis(2-phenylacetate) (19). phenylacetic acid $(0.545 \mathrm{~g}, 4 \mathrm{mmol})$ was used as the acid. The final product was an oil and was used as is. $0.69 \mathrm{~g}$ were obtained $\left(68 \%\right.$ yield). ${ }^{1} \mathrm{H}$ NMR (Chloroform- $d$ ) $\delta 7.44-7.05(\mathrm{~m}, 10 \mathrm{H}), 3.63(\mathrm{~s}, 4 \mathrm{H}), 1.84-0.36(\mathrm{~m}, 18 \mathrm{H})$.

Dibutylstannanediyl bis(2,2-diphenylacetate) (20). diphenylacetic acid $(0.849 \mathrm{~g}, 4 \mathrm{mmol})$ was used as the acid. The final product was an oil and was used as is. $0.77 \mathrm{~g}$ were obtained $(59 \%$ yield $) .{ }^{1} \mathrm{H} \quad \mathrm{NMR}$ (Chloroform- $d) \delta 7.40-7.13(\mathrm{~m}, 20 \mathrm{H}), 5.07(\mathrm{~s}, 2 \mathrm{H})$, $1.73-0.64(\mathrm{~m}, 18 \mathrm{H})$.

Dibenzyldibromostannane (21). this procedure was adapted from the literature. ${ }^{19}$ Tin powder $(10 \mathrm{~g}, 84 \mathrm{mmol})$ and anhydrous toluene $(100 \mathrm{~mL})$ were added to a $250-\mathrm{mL}$ three necked round-bottom flask equipped with a stir bar and reflux condenser. The mixture was heated to 
$105^{\circ} \mathrm{C}$ in an oil bath. $1 \mathrm{~mL}$ water was added to the mixture to initiate reflux. Benzyl bromide $(14.37 \mathrm{~g}$, $84 \mathrm{mmol}$ ) was added to the refluxing solution over $10 \mathrm{~min}$. The reflux was maintained for $3 \mathrm{~h}$. Unreacted tin was filtered off and white fluffy needles formed upon cooling of the reaction mixture. The solids were washed with cold toluene and dried overnight on high vacuum. $20 \mathrm{~g}$ were obtained $(52 \%$ yield $) .{ }^{1} \mathrm{H}$ NMR (Chloroform-d) $\delta$ 7.32-6.94 (m, 10H), $3.21(\mathrm{~s}, 4 \mathrm{H})$.

\section{Acknowledgments}

We would like to thank Sematech for financial support of this work. We would like to thank DuPont for supplying us with ESCAP polymer and King Industries for supplying us with a thermal acid generator for organic underlayers. We would also like to thank Michaela Vockenhuber for providing assistance at PSI. Finally, we would like to thank Patrick Naulleau at the Lawrence Berkeley National Laboratory for providing us with SuMMIT Lithography Image Analysis software. Part of this work was performed at SLS, Switzerland.

\section{References}

1. H. Ito, "Chemical amplification resists: history and development within IBM," IBM J. Res. Dev. 44(1/2), 119 (2000).

2. D. Brock, "Patterning the world," 2010, http://www.chemheritage .org/discover/media/magazine/articles/25-3-patterning-the-world.aspx? page $=1$.

3. G. Moore, "Cramming more components onto integrated circuits," Electronics 38 (1965).

4. P. Gargini, "International technology roadmap for semiconductors," 2014, http://www.itrs.net/.

5. K. Sakai et al., "Progress of high index immersion exposure system," In 5th Int. Symp. on Immersion Lithography Extensions, The Hague, Netherlands (2008)

6. R. L. Brainard et al., "Multiple anion nonvolatile acetal (MANA) resists," J. Photopolym. Sci. Technol. 14(4), 531 (2001).

7. E. Gullikson, Center for X-ray optics (CXRO) filter transmission, 1995 2010, http://henke.lbl.gov/optical_constants/filter2.html.

8. M. Neissar et al., "The physics of EUV photoresist and how it drives strategies for improvement," J. Photopolym. Sci. Technol. 25, 87 (2012).

9. J. Paul et al., "High resolution patterning for sub $30 \mathrm{~nm}$ technology nodes using a ceramic based dual hard mask," The Electrochemical Society Abstract 50, 21 2013).

10. J. Paul et al., "Evaluation of an advanced dual hard mask stack for high resolution pattern transfer," Proc. SPIE 8685, 86850V (2013).

11. G. Sandhu et al., "Triorganotin (IV) benzoates and aminobenzoates," $J$. Organomet. Chem. 321, 15 (1987).
12. A. Meriem et al., "Synthesis, characterization and in vitro antitumour activity of di-n-butyltin(;iv) derivatives of some aromatic carboxylic acids, including aspirin," Appl. Organomet. Chem. 5, 195 (1991).

13. B. Cardineau et al., "Photolithographic properties of tin-oxo clusters using extreme ultraviolet light (13.5 nm)," Microelectron. Eng. 127, 44 (2014)

14. J. Passarelli et al., "High-sensitivity molecular organometallic resist for EUV (MORE)," Proc. SPIE 9425, 94250T (2015).

15. A. Gaydon, Dissociation Energies and Spectra of Diatomic Molecules, 2nd ed., Chapman and Hall, London (1953).

16. M. Szwarc, "The determination of bond dissociation energies by pyrolytic methods," Chem. Rev. 47, 75 (1950).

17. T. Cottrell, The Strengths of Chemical Bonds, 2nd ed., Butterworth, London (1958)

18. Y. Ekinci, "EUV interference lithography," (2012), http://www.psi.ch/ lmn/euv-interference-lithography

19. P. Boudjouk et al., "Benzyl-substituted tin chalcogenides. Efficient single-source precursors for tin sulfide, tin selenide, and $\mathrm{Sn}\left(\mathrm{S}_{x} \mathrm{Se}_{1-x}\right)$ solid solutions," Chem. Mater. 8, 1189 (1996).

Ryan Del Re received his MS degree in nanoscale engineering from SUNY Albany College of Nanoscale Sciences and Engineering in 2015. He is currently working at Intel in Hillsboro, Oregon.

James Passarelli was an undergraduate student at the State University of New York (SUNY) Polytechnic University at the time this work was completed. He graduated in May 2015 and is currently pursuing his PhD in material science at Northwestern University.

Miriam Sortland graduated with a BS in nanotechnology from the University of Bergen, Norway, in 2012. She was a graduate student at the College of Nanoscale Science and Engineering at the time this work was completed, and she finished her MS degee in nanoengineering there in 2015 . She is now pursuing a career in a nonscientific field.

Daniel A. Freedman received his BA degree in chemistry from Macalester College and his $\mathrm{PhD}$ in inorganic chemistry from the University of Minnesota with Professor Kent Mann. He joined the faculty in the Chemistry Department at SUNY New Paltz in 1999. In 2012 he was appointed dean of the School of Science and Engineering and director of the Hudson Valley Advanced Manufacturing Center at SUNY New Paltz in 2013. His research interests include the synthesis and photochemistry of inorganic compounds.

Robert L. Brainard received his BS in chemistry from U.C. Berkeley in 1979. He studied the reaction mechanisms of organoplatinum compounds during his graduate studies with Professor $\mathrm{G}$. Whitesides at MIT and Harvard University. Following his postdoctoral studies with Professor R. Madix at Stanford University, he worked for Polaroid and Shipley/RHEM in the areas of DUV, EUV, and e-beam photoresists. He is now a professor at CNSE investigating new materials for use in EUV lithography.

Biographies for the other authors are not available. 